\title{
Socioeconomic Variations in Use of Prescription Medicines for COPD: A Register-Based Study
}

\author{
Ramune Jacobsen PhD, Ola Ekholm MSc, Niels K Rasmussen MSc, Ebba Holme Hansen MSc, \\ and Anne Frølich MD PhD
}

\begin{abstract}
BACKGROUND: The purpose of this study was to examine socioeconomic variations in the use of prescription medicines among elderly subjects with COPD. METHODS: Data from the Danish national administrative registers were used. The study population included 1,365 individuals $>60 \mathrm{y}$ old residing in the Municipality of Copenhagen and diagnosed with COPD in a hospital setting in 2007. Logistic regression analysis was applied to examine the associations between the use of all prescription medicines for obstructive pulmonary diseases and the use of long-acting bronchodilators, in subject groups of different socioeconomic position. RESULTS: The study demonstrated that approximately $90 \%$ of subjects with COPD purchased at least one prescription medicine for obstructive pulmonary diseases, whereas approximately $\mathbf{5 0 \%}$ purchased a long-acting bronchodilator. Medicine use did not vary according to educational status or personal wealth. CONCLUSIONS: There were no systematic socioeconomic differences in the use of relevant prescription medicines in elderly subjects diagnosed with COPD in hospital settings in Copenhagen. However, our findings indicate a gap between guideline recommendations and observed use of long-acting bronchodilators and hence suboptimal quality of treatment in the elderly COPD population. Key words: COPD; medicine; bronchodilators; elderly; socioeconomic factors; registries; Denmark. [Respir Care 2016;61(7):943-949. (c) 2016 Daedalus Enterprises]
\end{abstract}

\section{Introduction}

COPD is one of the most common and disabling chronic diseases, entailing poor health-related quality of life and high costs to society. The estimated COPD prevalence among individuals $35 \mathrm{y}$ of age or older in developed countries ranges from 5 to $19 \%$, with the majority being in the vicinity of $10 \%$; in Denmark, it is $17.4 \%{ }^{1}$

\footnotetext{
Ms Jacobsen is affiliated with the Research Unit for Dietary Studies, Bispebjerg and Frederiksberg University Hospital, Frederiksberg, Denmark. Mr Ekholm is affiliated with the National Institute of Public Health, University of Southern Denmark, Copenhagen, Denmark. Mr Rasmussen is affiliated with the Department of Public Health, University of Copenhagen, Copenhagen, Denmark. Ms Hansen is affiliated with the Department of Pharmacy, University of Copenhagen, Copenhagen, Denmark. Dr Frølich is affiliated with the Research Unit for Chronic Conditions, Bispebjerg and Frederiksberg University Hospital, Copenhagen, Denmark.
}

The study was supported by a grant from the Department of Public Health, University of Copenhagen. The authors have disclosed no conflicts of interest.
COPD is an incurable disease. Lifestyle changes, such as smoking cessation and physical exercise, alongside treatments to relieve the symptoms, delay the progress of the disease and improve the individual's ability to stay active as well as prevent exacerbations and treat complications. ${ }^{2}$ The main COPD treatments include medication therapy and pulmonary rehabilitation. As outlined in the Danish national guidelines and the Global Initiative for Chronic Obstructive Lung Disease (GOLD) 2011 strategy document, medication therapy should depend on the severity of symptoms and include short-acting bronchodilators for mild disease stages, additional long-acting bronchodilators for

\footnotetext{
Supplementary material related to this paper is available at http:// www.rcjournal.com.

Correspondence: Ramune Jacobsen PhD, Research Unit for Dietary Studies, The Parker Institute, Bispebjerg and Frederiksberg University Hospital, Nordre Fasanvej 57, 2000 Frederiksberg, Denmark. E-mail ramune.jacobsen@ regionh.dk.
}

DOI: $10.4187 /$ respcare. 04335 
moderate disease stages, and additional inhaled corticosteroids (ICS) for severe and very severe disease stages. ${ }^{3}$ All guidelines recommend long-acting bronchodilators, both $\beta_{2}$ agonist (LABA) and anticholinergics (long-acting muscarinic antagonists) as baseline therapy for moderate to severe COPD stages in the clinically stable phase. ${ }^{4}$

Research on medication treatment of COPD has intensified during the past decades, and it has been shown that, if adequate, medicines efficiently prevent disease exacerbations, decrease the need for hospitalization, improve quality of life, and save health-care expenditures. ${ }^{5,6}$ Clinical trials have shown that both types of long-acting bronchodilators and LABA in combinations with ICS prevented exacerbations in subjects at risk, with relative risk reductions averaging $14-27 \%$ for each of these drugs relative to placebo. It has been suggested that a triple combination of ICS-LABA plus a long-acting muscarinic antagonist may provide additional benefit, although the results of various studies to date have been heterogeneous. ${ }^{7}$ Quality of life and lung function were best improved on combination inhalers (ICS-LABA) and least on ICS alone at 6 and at 12 months. $^{8}$

Most chronic diseases are unequally prevalent among different socioeconomic status groups of the population. Usually, this is found independent of whether education, occupation, employment status, or income and wealth are used as a measure of socioeconomic position. ${ }^{9}$ To a large extent, this phenomenon is caused by socially differentiated exposure and vulnerability. Also, the reverse effect of poor health and disease on educational attainment, the possibility of earning a good income, and the chances of acquiring a secure job with good opportunities for the future plays an important role in the association between health and socioeconomic status. ${ }^{10}$

When prevalence and burden of diseases in general, and of COPD in particular, are distributed unequally between various socioeconomic groups, relevant medicines of high quality should be distributed with at least the same frequency to individuals of various socioeconomic position. ${ }^{11,12}$ However, the variations in medicine use in subjects with COPD from different socioeconomic status groups have not been explored. Only one study looked at the use of tiotropium, a new generation long-acting bronchodilator, and found that those subjects who were in a better socioeconomic situation used more of the medicine. ${ }^{13}$

The purpose of this study was to examine socioeconomic variations in the use of prescription medicines in elderly subjects with COPD diagnosed in a hospital setting. We investigated the use of all medicines for obstructive pulmonary diseases and the use of long-acting bronchodilators in subject groups of different wealth and education levels. We chose to focus on long-acting bronchodilators as an effective medicine recommended by the

\section{QUICK LOOK}

\section{Current knowledge}

Prevalence and burden of COPD is distributed unequally between various socioeconomic status groups. Because adequate COPD medication treatment efficiently prevents exacerbations, decreases the need for hospitalization, improves quality of life, and saves health-care expenditures, relevant medicines should be distributed with at least the same frequency to individuals with COPD from various socioeconomic status groups.

\section{What this paper contributes to our knowledge}

There were no systematic differences in the use of relevant prescription medicines in various socioeconomic status groups among elderly subjects with COPD diagnosed in a hospital setting in Copenhagen. However, our findings indicate a gap between guideline recommendations and actual use of long-acting bronchodilators and hence suboptimal quality of treatment in the elderly COPD population.

GOLD guidelines for all individuals with COPD in the moderate to severe disease stage. We investigated medicine use in the elderly as the most vulnerable group of subjects with COPD.

\section{Methods}

\section{Study Population and Data Sources}

The study population included all individuals $>60$ y old in the Municipality of Copenhagen who had contact with a hospital system due to a COPD diagnosis (action diagnosis ICD 10: J44) in 2007. Data were obtained from the Danish National Patient Register. ${ }^{14}$ In total, 1,365 individuals met the inclusion criteria (age range 61-101 y). Data on sex, age, and marital status were obtained from the Danish Civil Registration System. ${ }^{15}$

Data on prescription medicine purchases were retrieved on an individual level from the Danish Register of Medicinal Products Statistics. ${ }^{16}$ Since 1994, information on all prescription medication sold in Danish community pharmacies has been recorded in the Danish Register of Medicinal Products Statistics. The Register contains information on dispensed prescriptions, including variables at the level of the medicine user, the prescriber, and the pharmacy. Reimbursement-driven record keeping, with automated bar code-based data entry, provides data of high quality. The possibility of linkage through the unique Civil Personal Registration number with other nationwide indi- 


\section{Socioeconomic Variations in COPD Medicine Use}

vidual-level data sources makes the Danish Register of Medicinal Products Statistics a very powerful pharmacoepidemiological tool. Moreover, the linkage through the unique Civil Personal Registration number enables researchers to identify and follow prescriptions on the individual level over time. Thus, for individuals with permanent residence in Denmark, loss to follow-up is unlikely. In our study, medicines for obstructive airway diseases were defined by the Anatomical Therapeutic Chemical Classification System code R03. Long-acting bronchodilators were defined by the Anatomical Therapeutic Chemical codes R03AC12R03AC18 (LABA), R03BB04 (long-acting muscarinic antagonist), and R03BB05 (long-acting muscarinic antagonist). The exposure time was calculated from January 1 until December 31, 2007, or until death or emigration during 2007.

Data on the highest completed education level were obtained from the Population Education Register. ${ }^{17}$ Education was categorized into 3 levels: basic school, upper secondary/vocational school, and higher education. Personal net wealth (excluding pension fund assets) in 2006 was obtained from the Income Statistics Register and separated into quartiles. ${ }^{18}$

The 17-item Charlson comorbidity index was used to adjust for comorbidity. ${ }^{19}$ The Danish National Patient Register was used to identify the first-listed diagnoses for all hospital contacts in 2006.

\section{Statistical Analyses}

Multiple logistic regression in SAS 9.1 (SAS Institute, Cary, North Carolina) was applied to carry out the analyses. The models (with an outcome of use versus non-use of all medicines for obstructive pulmonary diseases as well as use versus non-use of long-acting bronchodilators) and explanatory variables (demographic characteristics and the comorbidity index) were run separately for education and personal wealth. We used separate models for education and personal wealth to estimate the total effect of education and wealth, respectively.

\section{Ethical Considerations}

The Danish Data Protection Agency gave permission for data retrieval and analysis (J. nr. 2009-41-4071). According to Danish law, permission from an ethics committee was not required, since biological material was not used in the present study.

\section{Results}

Table 1 presents the main characteristics of the study population. Tables 2 and 3 present the percentages of medicine non-users in each socioeconomic status group
Table 1. Characteristics of Study Population

\begin{tabular}{lr}
\hline \multicolumn{1}{c}{ Characteristics } & $\begin{array}{r}n(\%) \text { of } \\
\text { Subjects }\end{array}$ \\
\hline Access to prescription medicines & \\
All medicines for obstructive pulmonary diseases & $1,208(88.5)$ \\
Long-acting bronchodilators & $705(51.6)$ \\
Sex & \\
Men & $506(37.1)$ \\
Women & $859(62.9)$ \\
Age & \\
61-69 y & $294(21.5)$ \\
$70-79$ y & $608(44.5)$ \\
80-101 y & $463(33.9)$ \\
Marital status & \\
Married & $409(30.0)$ \\
Divorced & $493(35.1)$ \\
Widowed & $377(27.6)$ \\
Unmarried & $84(6.2)$ \\
Missing information & $2(0.1)$ \\
Highest completed education & \\
Basic school & $719(52.7)$ \\
Upper secondary or vocational school & $360(26.4)$ \\
Higher education & $94(6.9)$ \\
Missing information & $192(13.3)$ \\
Charlson comorbidity index & \\
1 2 & $1,007(73.8)$ \\
Total 3 & $199(14.6)$ \\
\hline & $159(11.6)$ \\
\hline & $1,365(100.0)$ \\
\hline
\end{tabular}

and the results of the logistic regression models investigating the association between socioeconomic characteristics and the use of medicines for obstructive pulmonary diseases as well as the use of long-acting bronchodilators, respectively. Regression model 1 is for education, and model 2 is for net wealth. According to the results presented in the tables, education and net wealth were not associated with medicine non-use, whereas subjects' age, sex, marital status, and comorbidities were. Subjects $\geq 80$ y old were more likely to not use the medicines than younger ones; males were more likely to not use the medicines than women; divorced, widowed, or unmarried subjects were more likely than married individuals to not use the medicines; and subjects with the most comorbidities were more likely to not use the medicines than subjects with fewer comorbidities.

\section{Discussion}

In our study, we observed that during a year, almost $90 \%$ of subjects with COPD purchased a COPD medicine, whereas only about $50 \%$ purchased any long-acting bronchodilator (Table 1). The national guidelines from the National Board of Health for COPD, which are 
Table 2. Percentage of Those Who Did Not Purchase a Prescription of Medicines for Obstructive Pulmonary Diseases According to Demographic and Socioeconomic Factors and Results of Multiple Logistic Regression Analyses

\begin{tabular}{|c|c|c|c|c|c|c|c|}
\hline \multirow{2}{*}{ Characteristics } & \multirow{2}{*}{ Percentage } & \multicolumn{3}{|c|}{ Model 1: Education Level } & \multicolumn{3}{|c|}{ Model 2: Net Wealth } \\
\hline & & OR & $95 \% \mathrm{CI}$ & $P$ & OR & $95 \% \mathrm{CI}$ & $P$ \\
\hline Sex & & & & $<.001$ & & & .01 \\
\hline Men & 14.0 & 1.98 & $1.33-2.96$ & & 1.57 & $1.09-2.26$ & \\
\hline Women & 10.0 & Reference & Reference & & Reference & Reference & \\
\hline Age & & & & .048 & & & $<.001$ \\
\hline$\leq 69 \mathrm{y}$ & 11.2 & Reference & Reference & & Reference & Reference & \\
\hline $70-79 y$ & 8.4 & 0.80 & $0.49-1.30$ & & 0.85 & $0.53-1.37$ & \\
\hline$\geq 80 \mathrm{y}$ & 15.1 & 1.39 & $0.82-2.34$ & & 1.66 & $1.01-2.72$ & \\
\hline Marital status & & & & .048 & & & .02 \\
\hline Married & 9.1 & Reference & Reference & & Reference & Reference & \\
\hline Divorced & 11.1 & 1.37 & $0.82-2.31$ & & 1.55 & $0.95-2.53$ & \\
\hline Widowed & 11.6 & 1.53 & $0.91-2.57$ & & 1.40 & $0.87-2.25$ & \\
\hline Unmarried & 20.2 & 2.60 & $1.31-5.16$ & & 2.76 & $1.45-5.27$ & \\
\hline Charlson comorbidity index & & & & .08 & & & .01 \\
\hline 1 & 9.7 & Reference & Reference & & Reference & Reference & \\
\hline 2 & 15.1 & 1.39 & $0.83-2.33$ & & 1.59 & $1.01-2.49$ & \\
\hline$\geq 3$ & 16.4 & 1.75 & $1.04-2.95$ & & 1.84 & $1.14-2.98$ & \\
\hline Education & & & & .84 & ND & ND & \\
\hline Basic school & 10.4 & Reference & Reference & & & & \\
\hline Upper secondary or vocational school & 10.8 & 0.98 & $0.65-1.50$ & & & & \\
\hline Higher education & 12.8 & 1.21 & $0.62-2.36$ & & & & \\
\hline Net wealth & & ND & ND & & & & .40 \\
\hline Lowest quartile & 12.0 & & & & Reference & Reference & \\
\hline Middle-low quartile & 9.1 & & & & 0.68 & $0.41-1.14$ & \\
\hline Middle-high quartile & 13.2 & & & & 1.01 & $0.63-1.63$ & \\
\hline Highest quartile & 10.8 & & & & 0.88 & $0.54-1.45$ & \\
\hline $\begin{array}{l}\text { Medicines for obstructive airway diseases were define } \\
\mathrm{OR}=\text { odds ratio } \\
\mathrm{ND}=\text { no data }\end{array}$ & natomical The & Chemical $\mathrm{Cl}_{2}$ & in System & & & & \\
\hline
\end{tabular}

in line with the international GOLD guidelines, recommend that patients with moderate, severe, and very severe COPD, who are usually diagnosed in a hospital setting, should be treated with long-acting bronchodilators. ${ }^{20}$ Thus, we observed a gap between guideline recommendations and actual use of long-acting bronchodilators in elderly subjects with COPD, which indicated suboptimal quality of treatment.

We further aimed to investigate whether different educational levels and the level of personal wealth were associated with the use of prescription medicines for COPD. Our results indicated that there were no systematic socioeconomic differences in the use of relevant COPD medicines in primary care; neither education nor personal wealth were associated with the use of prescription medicines. The Danish health-care and medicine reimbursement system can be mentioned among the explanatory factors behind our results. The Danish health-care system is predominantly public, financed mainly by local and national taxes. Access to hospitals and general practitioners is free of charge for all residents; dental care, pharmaceuticals, and some other services (eg, physiotherapy) require a copayment. In 2002, the Danish Government released a public health policy document titled "Health throughout life: the targets and strategies for public health policy of the Government of Denmark 2002-2010," placing a special focus on efforts to reduce the major preventable diseases, particularly type 2 diabetes, cardiovascular diseases, preventable cancers, musculoskeletal disorders, mental disorders, asthma, allergy, and COPD. According to the disease management plan for COPD, developed following the government policy document, smokers or ex-smokers $>35 \mathrm{y}$ of age who have one or more pulmonary symptoms should be examined by their general practitioner. After diagnosis of COPD, the severity of the disease should be assessed and regularly followed up in yearly controls. Based on the severity of the COPD, the general practitioner should decide whether to take on the individual's case or to refer him/her to a pulmonary specialist in the out-patient department in a hospital. Accordingly, the general practitioner or a pulmonologist will prescribe medicines for COPD. In the case of exacerbations, the individual will be hospi- 
Table 3. Percentage of Those Who Did Purchase a Prescription of a Long-Acting Bronchodilator According to Demographic and Socioeconomic Factors and Results of Multiple Logistic Regression Analyses

\begin{tabular}{|c|c|c|c|c|c|c|c|}
\hline \multirow{2}{*}{ Characteristics } & \multirow{2}{*}{ Percentage } & \multicolumn{3}{|c|}{ Model 1} & \multicolumn{3}{|c|}{ Model 2} \\
\hline & & OR & $95 \% \mathrm{CI}$ & $P$ & OR & $95 \% \mathrm{CI}$ & $P$ \\
\hline Sex & & & & .02 & & & .12 \\
\hline Men & 54.2 & 1.37 & $1.06-1.77$ & & 1.20 & $0.95-1.52$ & \\
\hline Women & 50.2 & Reference & Reference & & Reference & Reference & \\
\hline Age & & & & .048 & & & $<.001$ \\
\hline$\leq 69 y$ & 49.0 & Reference & Reference & & Reference & Reference & \\
\hline $70-79 y$ & 47.4 & 0.96 & $0.72-1.29$ & & 1.00 & $0.75-1.32$ & \\
\hline$\geq 80 \mathrm{y}$ & 59.0 & 1.37 & $0.97-1.92$ & & 1.56 & $1.14-2.15$ & \\
\hline Marital status & & & & .16 & & & .13 \\
\hline Married & 48.4 & Reference & Reference & & Reference & Reference & \\
\hline Divorced & 49.9 & 1.19 & $0.88-1.62$ & & 1.16 & $0.86-1.55$ & \\
\hline Widowed & 53.8 & 1.32 & $0.97-1.80$ & & 1.20 & $0.90-1.60$ & \\
\hline Unmarried & 61.9 & 1.19 & $0.88-1.62$ & & 1.77 & $1.09-2.88$ & \\
\hline Charlson comorbidity index & & & & .39 & & & .22 \\
\hline 1 & 50.2 & Reference & Reference & & Reference & Reference & \\
\hline 2 & 55.8 & 1.14 & $0.81-1.60$ & & 1.22 & $0.89-1.66$ & \\
\hline$\geq 3$ & 56.0 & 1.26 & $0.88-1.81$ & & 1.28 & $0.91-1.80$ & \\
\hline Education & & & & .30 & ND & $\mathrm{ND}$ & \\
\hline Basic school & 51.9 & Reference & Reference & & & & \\
\hline Upper secondary or vocational school & 47.8 & 0.83 & $0.64-1.07$ & & & & \\
\hline Higher education & 47.9 & 0.83 & $0.54-1.29$ & & & & \\
\hline Net wealth & & ND & ND & & & & .73 \\
\hline Lowest quartile & 51.9 & & & & Reference & Reference & \\
\hline Middle-low quartile & 50.4 & & & & 0.87 & $0.64-1.19$ & \\
\hline Middle-high quartile & 54.0 & & & & 0.99 & $0.72-1.35$ & \\
\hline Highest quartile & 50.3 & & & & 0.88 & $0.64-1.20$ & \\
\hline $\begin{array}{l}\text { Anatomical Therapeutic Chemical Classification Systen } \\
\text { OR }=\text { odds ratio } \\
\text { ND }=\text { no data }\end{array}$ & $\mathrm{R} 03 \mathrm{AC} 12-\mathrm{R} 03$ & 03BB 04 , and $\mathrm{I}$ & & & & & \\
\hline
\end{tabular}

talized to receive care where all medicines and procedures are free of charge. ${ }^{21}$ With regard to the reimbursement of prescription medicines in primary care, the Danish system is complex. Many prescription medicines in Denmark are covered by general reimbursement (ie, patients receive reimbursement automatically). The general reimbursement sum depends on an annual personal expenditure on reimbursable medicines before deduction of reimbursement. For example, people spending $>3,280$ Danish kroner ( $\sim 440$ euros) per year on medicines, receive $85 \%$ reimbursement. Subjects with COPD may also receive individual reimbursement for the chronically ill. According to the rules for individual reimbursement for the chronically ill, people spending $>17,738$ Danish kroner (2,377 euros)/y on medicines receive $100 \%$ reimbursement. In some cases (eg, for pensioners of limited means), a subsidy for medicines from the municipality of residence can also be provided. The Danish regions pay for general and individual reimbursement as well as for the medicines used in hospitals. ${ }^{22}$
We used personal wealth as an indicator for economic situation. Personal wealth reflects the economic situation among the elderly better than does income. Moreover, wealth could be interpreted as an indication of a lifelong accumulation of financial resources, healthy living, and success. In this process, the association between wealth and health is probably circularly caused and reinforced. On one hand, a good position (and maybe fortune inherited or gained) leads to accumulation of further wealth and other resources, which helps in managing and coping with the disease without the use of medicines. Conversely, disease and poor health lessen the chances to obtain education and earn a good living, which therefore does not enable the accumulation of a fortune but results in the spending of any fortune one might have. Findings regarding the prime relevance of wealth as a proxy measure for economic position have been reported earlier in studies on health in aging populations. ${ }^{23}$ In addition, we also conducted analyses with personal income and found no differences in medicine 
use between the subjects of various incomes (data not shown).

Women appeared to use medicines, both all of the medicines for obstructive airway diseases and long-acting bronchodilators, more often than men (Tables 2 and 3). Marital status was associated with medicine use, so that being married had a positive impact on the use of long-acting bronchodilators compared with being divorced, widowed, or unmarried (Table 3). To be married indicates a stable and supportive social relation, which has been found to be related to adherent use of different medication types. ${ }^{24}$ Surprisingly, the oldest age group ( $\geq 80 \mathrm{y}$ ) and the groups with more comorbidities used medicines less often than the younger groups and the groups with fewer comorbidities, respectively (Tables 2 and 3). We expected that age and poorer general health would reduce general functional capacity, increase disease severity, and therefore require more intensive medicine use. The reasons why the oldest subjects used medicines less often than younger ones are not clear. We speculated that older subjects might have been spending more time in hospitals, where they might have been receiving their medicines, which are not registered at the individual level in the Danish Register of Medicinal Products Statistics; however, analyses adjusted for the frequency and length of hospital stays showed essentially the same results as our main analyses. We further speculated that elderly subjects more often resided in nursing homes, but the Danish Register of Medicinal Products Statistics, unlike prescription registers in other countries, does contain individual-level information on prescriptions dispensed to residents of long-term care institutions, such as nursing homes. Therefore, it is likely that elderly subjects with COPD in Copenhagen actually did not purchase any medication for their disease more often than younger ones, and this is a problem that requires further investigation.

A couple of studies from Denmark have previously described the Danish COPD population. ${ }^{25,26}$ The distributions of prevalence of COPD according to age groups in our study and the other Danish studies were similar (see supplementary Table 1 at http://www.rcjournal.com).

\section{Limitations of the Study}

Several methodological considerations of the study have to be mentioned. First, the medicines in the prescription registry, from where we retrieved our data, were the medicines dispensed in community pharmacies and hence did not include any medicines dispensed in hospitals. The sensitivity analysis, including COPD-specific hospital days in regression models, did not reveal any changes in the estimates, thus providing support to the conclusions being independent of the medicines used during COPD hospitalization(s). Second, in our analyses, we did not adjust for
COPD disease severity. Disease severity in subjects with COPD is determined by their lung function. The information on lung function started being reported to the National Patient Registry from 2008 only for out-patients with COPD. ${ }^{27}$ We used data from 2007; moreover, we analyzed both in- and out-patients. Thus, data on disease severity in our study were not available. Nevertheless, all patients with COPD of moderate to severe disease stages according to GOLD guidelines (ie, the subjects in our study) are recommended treatment with long-acting bronchodilators besides other medications for COPD, regardless of COPD disease stage. We reported analyses of medication use versus non-use as well as long-acting bronchodilator use versus non-use (ie, dichotomous outcomes not required to be adjusted for disease severity). We also conducted linear regression analyses to see whether the amount of all medicines as well as long-acting bronchodilators depended on socioeconomic characteristics. The amount of medicines used, however, does depend on disease stage; therefore, the analyses ideally should be adjusted for disease severity. Because the information on the latter was not available, adjustment was not possible. However, our analyses did not reveal any differences in the amount of all medicines, as well as the amount of long-acting bronchodilators, used in the subject groups with different education, whereas those with larger net wealth used smaller amounts of medicines than those with less wealth (supplementary Table 2).

Finally, a limitation of the study was that approximately $13 \%$ of our population did not have information available on education. This is due to the fact that Danish administrative registers only contain information on education for individuals born since 1921. Consequently, individuals in our study who in 2007 were $\geq 86$ y old had no information on education and were excluded from the relevant analyses.

\section{Implications of the Study}

It has been demonstrated that only about $50 \%$ of the COPD population in Denmark received evidence-based care as recommended in the national guidelines. ${ }^{20}$ The chronic care model has been envisioned as a possible solution to encourage high-quality chronic disease care. ${ }^{28} \mathrm{~A}$ systematic literature review of the effects of using the chronic care model to support care in the COPD population concluded that $\geq 2$ of 4 groups of management practices (ie, self-management, delivery system design, decision support, and clinical information system) need to be implemented for that reason. ${ }^{29}$ Moreover, improving care in COPD patients might be linked to changing the care system. ${ }^{30}$ In this context, the findings of our study point out the groups of elderly subjects with COPD (namely very old, divorced, widowed or unmarried, and men) who 


\section{Socioeconomic Variations in COPD Medicine Use}

should be considered when trying to improve (ie, implement new or change existing) practices of chronic care.

\section{Conclusions}

Our study could not identify any systematic socioeconomic barriers to the use of pulmonary prescription medications in elderly subjects with COPD in Copenhagen. However, our findings indicate a gap between guideline recommendations and actual use of long-acting bronchodilators and hence suboptimal quality of treatment in the elderly COPD population.

\section{REFERENCES}

1. Fabricius P, Løkke A, Marott JL, Vestbo J, Lange P. Prevalence of COPD in Copenhagen. Respir Med 2011;105(3):410-417.

2. Decramer M, Janssens W, Miravitlles M. Chronic obstructive pulmonary disease. Lancet 2012;379(9823):1341-1351.

3. Vestbo J, Titlestad IL. [Medical treatment of COPD]. Ugeskr Laeger 2013;175(18):1261-1264

4. Nardini S, Camiciottoli G, Locicero S, Maselli R, Pasqua F, Passalacqua $\mathrm{G}$, et al. COPD: maximization of bronchodilation. Multidiscip Respir Med 2014;9(1):50.

5. Bilde L, Rud Svenning A, Dollerup J, Baekke Borgeskov H, Lange P. The cost of treating patients with COPD in Denmark: a population study of COPD patients compared with non-COPD controls. Respir Med 2007;101(3):539-546.

6. Moll L, Lange P, Dahl BH. KOL: sygdom, behandling og organisation [COPD: disease, treatment and organisation]. København: Munksgaard Danmark; 2011.

7. Aaron SD. Management and prevention of exacerbations of COPD. BMJ 2014;349:g5237.

8. Kew KM, Dias S, Cates CJ. Long-acting inhaled therapy ( $\beta$-agonists, anticholinergics and steroids) for COPD: a network meta-analysis. Cochrane Database Syst Rev 2014;(3):CD010844.

9. Diderichsen F, Andersen I, Manuel C. Ulighed i sundhed: Årsager og Indsatser [Health inequality: causes and consequences]. København: Sundhedsstyrelsen; 2011.

10. Rasmussen N.K. Sociale forskelle [Social disparities]. In: Kjøller M, Juel K, Kamper-Jørgensen F, editors. Folkesundhedsrapporten Danmark 2007 [The Public Health Report Denmark 2007]. København: Statens Institut for Folkesundhed; 2007:433-437.

11. Commission on Social Determinants of Health. Closing the gap in a generation: health equity through action on the social determinants of health. Geneva: World Health Organization; 2008.

12. Sundhedsloven, Lovbekendtgørelse [Health Law Legislation] nr. 913. 2013.

13. Blanc PD, Eisner MD, Yelin EH, Earnest G, Balmes JR, Gregorich SE, Katz PP. Socioeconomic gradients in tiotropium use among adults with COPD. Int J Chron Obstruct Pulmon Dis 2008;3(3):483490.

14. Lynge E, Sandegaard JL, Rebolj M. The Danish National Patient Register. Scand J Public Health 2011;39(7 Suppl):30-33.

15. Pedersen CB. The Danish Civil Registration System. Scand J Public Health 2011;39(7 Suppl):22-25.

16. Kildemoes HW, Sørensen HT, Hallas J. The Danish National Prescription Registry. Scand J Public Health 2011;39(7 Suppl):38-41.

17. Jensen VM, Rasmussen AW. Danish Education Registers. Scand J Public Health 2011;39(7 Suppl):91-94.

18. Baadsgaard M, Quitzau J. Danish registers on personal income and transfer payments. Scand J Public Health 2011;39(7 Suppl):103-105.

19. Charlson ME, Pompei P, Ales KL, MacKenzie CR. A new method of classifying prognostic comorbidity in longitudinal studies: development and validation. J Chronic Dis 1987;40(5):373-383.

20. Sundhedsstyrelsen. KOL: kronisk obstruktiv lungesygdom: anbefalinger for tidlig opsporing, opfølgning, behandling og rehabilitering [COPD: chronic obstructive pulmonary disease: recommendations for early diagnosis, follow-up, treatment and rehabilitation]. Københanv: Sundhedsstyrelsen; 2007.

21. Schiotz M, Frølich A, Krasnik A. Denmark. In: Nolte E, Knai C, KcKee M, editors. Managing chronic conditions: experience in eight countries. Copenhagen: World Health Organization; 2008:15-28.

22. Danish Health and Medicine Authority. Reimbursement of medicines. April 24, 2012. https://sundhedsstyrelsen.dk/en/medicines/ reimbursement. Accessed August 8, 2015.

23. Avlund K, Holstein BE, Osler M, Damsgaard MT, Holm-Pedersen P, Rasmussen NK. Social position and health in old age: the relevance of different indicators of social position. Scand J Public Health 2003; 31(2):126-136.

24. DiMatteo MR. Social support and patient adherence to medical treatment: a meta-analysis. Health Psychol 2004;23(2):207-218.

25. Christensen AI, Ekholm O, Davidsen M, Juel K. Sundhed og sygelighed i Danmark 2010 og udviklingen siden 1987 [Health and morbidity in Denmark 2010 and development since 1987]. Copenhagen: National Institute of Public Health; 2012.

26. Lange P, Marott JL, Dahl M, Ingebrigtsen TS, Vestbo J, Nordestgaard BG. Substantial need for early diagnosis, rehabilitation and treatment of chronic obstructive pulmonary disease. Dan Med J 2012; 59(4):A4396.

27. Tottenborg SS, Johnsen SP, Thomsen RW, Nielsen H, Hansen EF, Lange P. Use of non-invasive ventilation is increasing in patients admitted with a chronic obstructive pulmonary disease exacerbation. Dan Med J 2013;60(8):A4686.

28. Robert Wood Johnson Foundation. Improving chronic illness care. http://improvingchroniccare.org. 2014. Accessed February 16, 2014.

29. Adams SG, Smith PK, Allan PF, Anzueto A, Pugh JA, Cornell JE. Systematic review of the chronic care model in chronic obstructive pulmonary disease prevention and management. Arch Intern Med 2007;167(6):551-561.

30. Committee on Quality of Health Care in America IoM. Crossing the quality chasm: a new health system for the 21 st century. Washington, DC: National Academy Press; 2001. 